\title{
Gongronema Latifolium: A Plant with Cardioprotective Potentials
}

\author{
Justin Atiang Beshel, ${ }^{1,2}$, Favour Nyoh Beshel ${ }^{1,2}$, Clement Oshie $\mathrm{Nku}^{2}$, Daniel Udofia Owu² \\ ${ }^{1}$ Department of Physiology, Faculty of Biomedical Sciences, Kampala International University, \\ Western Campus, Ishaka - Bushenyi District, Uganda \\ ${ }^{2}$ Department of Physiology, Faculty of Basic Medical Sciences, College of Medical Sciences, \\ University of Calabar, Calabar-Nigeria
}

\begin{abstract}
Gongronema latifolium $(G L)$ has gained research interest in the field of Medicine. The present study investigated the cardioprotective potentials of the ethanolic and ethyl acetate fraction of the leaves extract of G.L. 18 Male Wistar rats were divided equally into three groups. Group 1 was the control group, and was administered $0.9 \%$ normal saline. Group 2 was administered $200 \mathrm{mg} / \mathrm{kg}$ ethanolic leaves extract of $G L$. Group 3 received $200 \mathrm{mg} / \mathrm{kg}$ ethyl acetate fraction of the leaves extract of $G L$. Administration was via oral gavage and lasted for 14 days. The rats were sacrificed under chloroform anaesthesia. Blood was collected via cardiac puncture, allowed to clot, and later centrifuged to get serum. Laboratory assays were done for serum concentrations of total cholesterol (Tc), total triglycerides (Tg), high density lipoprotein (HDL-c), low density lipoprotein (LDL), malondialedyde (MDA), total antioxidant capacity (TAC), and total plasma peroxide (TPP). The heart, aorta, and kidneys were also harvested for organ weight and histological studies. Administration of $G L$ extracts resulted in an increase ( $p<0.001)$ serum concentrations of HDL-c and TAC, with a consequent reduction in the serum concentrations of Tg, LDL-c, VLDL, MDA, and TPP. There was no significant $(\mathrm{p}<0.01)$ change in organ weights of the heart, aorta, and kidneys across the groups. Histology of the blood vessels showed intact layers across the groups. There was no derangement of cellular architecture in the heart and kidney. This study therefore concludes that Gongronema latifolium leaves extract is cardioprotective, and thus provides a basis for the use of this plant as an alternative for the prevention, management or control of cardiovascular diseases.
\end{abstract}

Keywords: Cardioprotection, Gongronema latifolium, Cardiovascular diseases

\section{INTRODUCTION}

Protection of the heart and associated blood vessels has become a topical issue in the prevention of cardiovascular diseases (CVD). 17.7 million People die of CVD every year (WHO, 2017). In America, it is listed as the number one cause of death, and accounts for about 801,000 deaths annually (AHA, 2017). In Nigeria, current evidence suggests that 3 out of every five persons suffer from one form of cardiovascular disease or the other (). This trend projects CVD as a global menace and a major public health challenge in both developed and developing countries.

To curb this danger, WHO (2013) adopted a mechanism tagged "Global action plan for the prevention and control of Non Communicable Diseases (NCDs) 2013-2020". This plan aims to reduce the mortality rate from NCDs by $25 \%$ by 2025 with a major focus on the prevention and control of CVD. Despite the World acclaimed effort, unfortunately, CVD remains inadequately managed with orthodox drugs (Nwokocha et al., 2012).

Thus, many persons all over the world still resort to traditional form of medication in cardiovascular disorders. In a survey, 1,576 out of 9,566 respondents reported the use of traditional or alternative medicine for the past 12 months (UnÜtzer et al., 2012). In spite of the importation of Western medication, many Nigerians still use herbal remedies since it is strongly believed to be effective and affordable. There is a present shift by WHO and AU towards the integration of herbal medicine in the national health plan, and a renewed interest on the search for drugs from natural products and herbs as an alternative to the orthodox (Kumar et al., 2017).
Low intake of fruits and vegetables is associated with high mortality from CVD (Moller and Kaufman, 2005; Zimmet et al., 2005). Ramaraj and Chellapa (2008), in their study also posited that diets rich in fruits and vegetables protect against CVD. Nutraceuticals in the form of antioxidants, dietary fibres, omega-3 polyunsaturated fatty acids, vitamins and minerals also play a preventive and curative role in CVD (Choudhary and Tomer, 2013).

One of such plants used as a nutraceutical, with rich antioxidant properties is Gongronema latifolium. Gongronema latifolium Benth. (family Apocynaceae) is a tropical plant with proven medicinal properties (Ugochukwu and Babady, 2002; Morebise, 2015). Its common names are 'amaranth globe', in Nigeria, 'Utazi', 'Utasi' and 'Arokeke' or 'Madumaru' by the Ibos, Ibibios and Yorubas, respectively.

Gongronema latifolium is widely explored in the traditional folk medicine for various health conditions including hypertension (Morebise et al., 2002, Ugochukwu and Babady, 2002; Ugochukwu et al., 2003). It is used for the management of diabetes, diarrhea, ulcer and dyspepsia (Morebise et al., 2002, Ugochukwu et al., 2003). It has hypoglycemic and antioxidant effect, reduces oxidative stress and lipid peroxidation (Ugochukwu and Babady, 2002; Ugochukwu and Cobourne, 2003). It possesses antiulcer activity (Owu et al., 2012) and increases white blood cells count and hemoglobin concentration (Antai et al., 2009). G. latifolium has anti-inflammatory, anti-malarial, and antimicrobial activities (Morebise et al., 2002; Osuala et al., 2005; Akuodor et al., 2010). 
Phytochemical present in the leaves are alkaloids, saponins, flavonoids, tannins, and glycosides (Morebise et al., 2002; Atangwho et al., 2003; Schnieder et al., 2003; Eleyinmi and Bresseler, 2007); also polyphenols and reducing sugars (Antai et al., 2009).

Despite its folkloric use in blood pressure reduction, there is no scientific report validating its use in the prevention or treatment of CVD. This study therefore investigated the cardioprotective potentials of this plant. This is with a view to providing a scientific justification or otherwise for the possible use of this plant in the prevention, management or control of CVD.

\section{MATERIALS AND METHODS}

\section{Experimental animals/Design}

Male Wistar rats (200- $250 \mathrm{~g}, \mathrm{n}=18$ ) were used for the study. They were divided into 3 groups of 6 rats each. Group 1 served as the normal control placed on normal saline. Group 2 was administered $200 \mathrm{mg} / \mathrm{kg}$ of ethanol extract, group 3 received $200 \mathrm{mg} / \mathrm{kg}$ ethyl acetate fraction. Administration was via oral gavage, and lasted for two weeks. Approval was sought and consent granted by the Faculty of Basic Medical sciences Animal Research Ethics Committee, University of Calabar with Approval No: 019PY20317. The animals were kept in plastic cages and controlled environment $(12 \mathrm{~h}$ light/dark cycles at $27 \pm 2^{\circ} \mathrm{C}$ ) one week for acclimatization before commencement of the study. The rats had free access to normal rat chow and tap water ad libitum.

\section{Plant material and extraction}

Gongronema latifolium leaves were bought from a local market in Calabar, Nigeria. A voucher specimen was identified at the herbarium unit of the Department of Botany and deposited (GLB 4612) in the herbarium of the University of Calabar, Calabar, Nigeria. The leaves were washed with clean water and air-dried under shade. The dry leaves were ground into coarse powder. To prepare ethanol extract, 1.65 $\mathrm{Kg}$ of the powdered leaves was suspended in two litres of ethanol (BDH Ltd Poole, England) and left to percolate for 24 hours at room temperature. The suspension was thereafter filtered with Whattman No. I filter paper. The filtrate was evaporated by hot air oven treatment at $40-45^{\circ} \mathrm{C}$ to a thick dark gummy crude extract giving a yield of $66 \mathrm{~g}$ (4.8\%). For ethyl acetate fraction, $5 \mathrm{~g}$ of the ethanol extract was inserted into a mortar with warm distilled water, then stirred to form a suspension, and transferred into a separating funnel. The suspension was added $200 \mathrm{ml}$ of ethyl acetate and shaken to form two layers. The ethyl acetate soluble fraction was filtered over Whatmann No. 1 filter paper. The filtrate was also evaporated following same procedures for the ethanol extract. The extracts were refrigerated at $-4^{\circ} \mathrm{C}$ until required for use.

\section{Estimation of Cardioprotective Activity of GL}

At the end of the feeding period, the rats were fasted for 12 hours, and then sacrificed under chloroform anaesthesia. Blood was collected via cardiac puncture into sterile plain tubes, and allowed to clot at room temperature over one hour period. The blood was centrifuged at 400rpm for 10 minutes. Serum was collected into clean sample bottles for biochemical assays. Cardioprotective activity was evaluated by assessing some biochemical biomarkers related to the functionality of the heart such as Total cholesterol (Tc) [Siedel et al., 1983], Total triglycerides (Tg) [Sullivan et al., 1985], High Density Lipoprotein (HDL-c), Low Density
Lipoprotein (LDL-c) [Friedewald et al., 1992], Malondialdehyde (MDA) [Ohkawa et al., 1979], Total Antioxidant Capacity (TAC) [Frei, 1992]., and Total Plasma Peroxide (TPP). All analysis was performed using commercially available kits based on the references and Manufacturer's instructions using analyzer.

\section{Histological Studies}

After sacrifice, the heart, kidneys and aorta were harvested, washed in normal saline, and fixed in 10\% formalin for 24 hours. The organs were later transferred to $250 \mathrm{mls}$ of $70 \%$ alcohol, 95\% alcohol, and absolute alcohol to dehydrate the tissues. Equal ratio of xylene and alcohol (100mls for each) was introduced to the organs as the final step for dehydration. The organs were cleared with $100 \mathrm{mls}$ of xylene for 2 hours, and then impregnated in molten paraffin wax at a constant temperature of $50^{\circ} \mathrm{c}$ for 2 hours. At the embedding stage, the organs were buried in pure paraffin wax to prepare them for sectioning. The molten paraffin was poured into an embedding mould and the organs immersed in it until the molten wax dried, and then the block was removed from the mold. The tissue blocks were then mounted on wooden blocks with the help of molten paraffin wax as an adhering media. The tissues were then sectioned at $5 \mu \mathrm{m}$ to produce thin ribbons. They were then floated on $40 \%$ alcohol briefly, and hot water bath at $48^{\circ} \mathrm{c}$. The tissues were then mounted on slides already rubbed with egg albumen, and allowed to dry.

The sections were dewaxed using xylene, and rehydrated by passing them through columns of alcohol (absolute alcohol, 95\% alcohol, and 75\% alcohol) for two minutes each. They were then rinsed with water, and stained with haemotoxylin for 15 minutes. They were later rinsed, passed through acid alcohol, and immersed in eosin for 5 minutes. The sections were again dehydrated graded doses of alcohol arranged in ascending order. They were cleared in xylene, and mounted with Canada balsam. The H\&E stained sections were protected from scratches, and preserved for future use. Electron micrographs were performed using electron microscope, and photographed by photomicrography. The sections were then viewed under the Nikon Microscope, ECLIPSE E400, and model 115, Japan.

\section{Organ Weight Studies}

In another batch, the heart and kidneys were harvested and weigh using a digital weighing balance for rodents (BIOPAL Inc, Canada).

\section{Statistical Analysis}

The results are presented as mean \pm standard error of the mean. Data were analyzed using GraphPad prism software version 6.00 for Windows (GraphPad Software, San Diego, CA, USA). One-way analysis of variance with Turkey's posttest was performed, and probability level of $p<0.05$ was considered statistically significant.

\section{RESULTS}

Effect of ethanol extract and ethyl acetate fraction of $G L$ on serum total cholesterol

The mean serum total cholesterol in the control, $G L$, and ethyl acetate fraction groups was $1.84 \pm 0.02 \mathrm{mmol} / \mathrm{L}, 1.38 \pm$ $0.03 \mathrm{mmol} / \mathrm{L}$, and $1.92 \pm 0.02 \mathrm{mmol} / \mathrm{L}$ respectively. There was a significant $(\mathrm{p}<0.01)$ decrease serum total cholesterol in the $G L$ treated group when compared with the control and ethyl acetate fraction groups. This is presented in Figure 1. 
Effect of ethanol extract and ethyl acetate fraction of $G L$ on serum triglyceride level

The serum triglyceride level in the control, $G L$, and ethyl acetate fraction groups was $0.83 \pm 0.01 \mathrm{mmol} / \mathrm{L}, 0.59 \pm$ $0.01 \mathrm{mmol} / \mathrm{L}$, and $0.86 \pm 0.001 \mathrm{mmol} / \mathrm{L}$ respectively. The result showed a decrease $(\mathrm{p}<0.01)$ in triglyceride level in the group administered $G L$ compared with the control and ethyl acetate fraction groups. This is presented in Figure 2.

\section{Effect of ethanol extract and ethyl acetate fraction of $G L$} on serum high density lipoprotein-cholesterol

HDL-c level in the control, GL, and ethyl acetate fraction groups was $0.46 \pm 0.002 \mathrm{mmol} / \mathrm{L}, 0.48 \pm 0.008 \mathrm{mmol} / \mathrm{L}$, and $0.49 \pm 0.003 \mathrm{mmol} / \mathrm{L}$ respectively. The result showed a significant $(\mathrm{p}<0.01)$ increase level of HDL-c in the $G L$ treated groups compared with the control. This is presented in Figure 3.

\section{Effect of ethanol extract and ethyl acetate fraction of $G L$ on serum LDL-c}

The LDL-c levels in the control, GL, and ethyl acetate fraction groups were $0.75 \pm 0.006 \mathrm{mmol} / \mathrm{L}, 0.73 \pm 0.0004 \mathrm{mmol} / \mathrm{L}$, and $0.72 \pm 0.0004 \mathrm{mmol} / \mathrm{L}$ respectively. The result showed decrease $(\mathrm{p}<0.05)$ levels of LDL-c in the $G L$ treated groups compared with the control. This is presented in Figure 4.

\section{Effect of ethanol extract and ethyl acetate fraction of $G L$} on VLDL-c

VLDL-c level in the control, $G L$, and ethyl acetate fraction groups was $0.75 \pm 0.006 \mathrm{mmol} / \mathrm{L}, 0.73 \pm 0.004 \mathrm{mmol} / \mathrm{L}$, and $0.76 \pm 0.004 \mathrm{mmol} / \mathrm{L}$ respectively. The result presented a decreased $(\mathrm{p}<0.01)$ level of VLDL-c in the group administered GL compared with the control and ethyl acetate fraction groups. This is presented in Figure 5.

\section{Effect of ethanol extract and ethyl acetate fraction of $G L$} on serum malondialdehyde (MDA) levels

The serum MDA level in the control, GL, and ethyl acetate fraction groups was $0.42 \pm 0.01 \mathrm{nmol} / \mathrm{L}, 0.31 \pm 0.01 \mathrm{nmol} / \mathrm{L}$, and $0.26 \pm 0.01 \mathrm{nmol} / \mathrm{L}$ respectively. The result showed decrease levels of MDA $(\mathrm{p}<0.01)$ in the extract treated groups compared with the control. This is presented in Figure 6.

\section{Effect of ethanol extract and ethyl acetate fraction of $G L$} on total antioxidant capacity (TAC)

TAC values for the control, $G L$, and ethyl acetate fraction groups were $5.0 \pm 0.1 \mu \mathrm{mol} / \mathrm{L}, 6.4 \pm 0.2 \mu \mathrm{mol} / \mathrm{L}$, and $8.0 \pm$ $0.2 \mu \mathrm{mol} / \mathrm{L}$ respectively. The extract treated groups had significant $(\mathrm{p}<0.01)$ higher total antioxidant capacity when compared with the control. This is presented in Figure 7.

\section{Effect of ethanol extract and ethyl acetate fraction of $G L$} on total plasma peroxide (TPP)

TPP in the control, $G L$, and ethyl acetate fraction groups was $85.0 \pm 1.5 \mu \mathrm{mol} / \mathrm{L}, 70 \pm 1.4 \mu \mathrm{mol} / \mathrm{L}$, and $44 \pm 2.5 \mu \mathrm{mol} / \mathrm{L}$ respectively. The extract treated groups showed a significant $(p<0.01)$ decrease levels of TPP in comparison with the control group. This is presented in Figure 8.

\section{Effect of ethanol extract and ethyl acetate fraction of $G L$ on Heart and Kidney weights}

The weight of the heart for the control, $G L$, and ethyl acetate fraction groups were $0.0032 \pm 0.0001 \mathrm{~g}, 0.0033 \pm 0.0001 \mathrm{~g}$, and $0.0031 \pm 0.0001 \mathrm{~g}$ respectively; and organ weight of the kidney across the groups were $0.0063 \pm 0.0001 \mathrm{~g}, 0.0065 \pm$ $0.0003 \mathrm{~g}$ and $0.0067 \pm 0.0001 \mathrm{~g}$ respectively. Result showed no statistical difference in weight of the organs across the groups. This is presented in Figures 9 and 10.

Photomicrographs of the heart, kidney, and aorta treated with ethanol extract and ethyl acetate fraction of GL

Plates 1A, 1B, and 1C present the photomicrograph of the heart in the control, $G L$ ethanol extract, and ethyl acetate fraction groups respectively. The photomicrographs show intact cardiac myocytes in all the groups. The myocytes contain central ovoid nuclei with a clear zone at the poles. There are interdigitation of the muscle fibres and thin walled blood vessels. Thus $G L$ extract and its ethyl acetate fraction has no deleterious effect on the cardiac muscle.

Plates 2A, 2B, and 2C present the photomicrograph of the kidney in the control, ethanol extract, and ethyl acetate fraction groups respectively. The photomicrographs across the groups show kidneys with prominent glomeruli and renal tubules. There are intact bowman spaces lined by flattened epithelial cells. The renal tubules have intact basement membrane and epithelium. They are lined by columnar to cuboidal epithelium with intact lumen. The intervening interstitia have congested blood vessels. Consumption of $G L$ extracts therefore does not result in any renal impairment.

Plates 3A, 3B, and 3C present the photomicrograph of the aorta in the control, ethanol extract, and ethyl acetate fraction groups respectively. The photomicrographs across the groups show intact layers comprising the outer tunica adventitia with collagenous fibres, blood vessels and fibroblast. The intermediate tunica adventitia is thick and consists of regular arranged bundles of collagenous fibres with attached fibroblast. The tunica intima consists of intact simple end othelium overlying thin lamina propria.

\section{DISCUSSION}

The present study investigated the cardioprotective potentials of Gongronema latifolium leaves extract on normotensive Wistar rats. G. latifolium administration resulted in a decrease serum concentration of total cholesterol, low density lipoprotein, triglycerides, very low density lipoprotein, and an increase in the serum concentration of high density lipoprotein. Abnormal lipid metabolism is a major pathogenic factor for various cardiovascular diseases. Cholesterol for many years is reported to have a direct relationship with cardiovascular prognosis. An increase by $1 \%$ in total cholesterol, results in $2-3 \%$ increase in coronary heart disease (Carlson, Bottiger and Ahfeldt, 1979). Recent studies have shown that total cholesterol increase by $10 \%$ results in coronary-related mortality risk of about 38\% (Law, Wald and Thompson, 1994). LDL on the other hand, is emphasized to be highly implicated in coronary heart disease (ILIB, 2003) and forms a discriminating criterion for cardiovascular risk.

Reports also showcase a relationship between LDHcholesterol and triglycerides, indicating that in men, there is a 13\% increase in the risk of cardiovascular disease, while women have a $37 \%$ increase risk, all resulting from increased levels of triglycerides (Criqui, et al., 1993; Hokanson and Austin, 1996; Assman, Schulte and Eckardstein, 1996). 
On the contrary, HDL-cholesterol has an inverse relationship with the risk of coronary heart disease. There is a $2-3 \%$ decrease in the risk of cardiovascular disease for every $1 \mathrm{mg} / \mathrm{dl}$ elevation of HDL-Cholesterol (Gordon et al., 1989). HDL-cholesterol is involved in cholesterol reversal transport, possesses anti-inflammatory capacity and protects against LDL-cholesterol oxidation (Ansell et al., 2004). When the levels of HDL-cholesterol are low, the risk of cardiovascular diseases becomes prominent (Cui, et al., 2001).

Administration of Gongronema latifolium leaves extract also resulted in decrease serum concentrations of MDA, and total plasma peroxide, but caused an increase in the serum concentrations of total antioxidant capacity. This index points to the cardioprotective potentials of $G$. latifolium as an antioxidant, with abilities to mob up free radicals.Evidence abounds that abnormal production of ROS results in a cascade of cardiovascular disorders like cancer, coronary heart disorders, neurological disorders, and also involved in the process leading to physiological ageing (Pacher and Szabo, 2008; Vassalle et al., 2008).

Endothelial dysfunction due to a disruption in its vascular wall microenvironment is a principal concept of cardiovascular disease pathogenesis mediated by free radicals. The endothelium is a major part of the vasculature. It is responsible for the vascular tone regulation, inflammation, thrombosis, platelet activity, and atherosclerosis. The endothelial tone of the vasculature is a responsibility of substances like the endothelins, nitric oxide, endothelium-derived relaxation factor, and prostacyclins (Zorio et al., 2008). Reduction in nitric oxide bioavailability results in endothelial dysfunction, leading to paradoxical vasoconstriction (Zeiher et al., 1991). It is observed that persons with atherosclerosis and coronary artery disease, or those at risk for both coronary and peripheral vascular disease, have endothelial dysfunction (Schachinger, 1996). Studies have also shown that in renovascular hypertension, essential hypertension, pre-eclampsia and malignant hypertension, there is increased ROS production (Higashi et al., 2002; Lip et al., 2002; Zheng et al., 2003; Lee et al., 2003). Reactive oxygen species activities result in a direct cardiac injury due to oxidation of cellular constituents, diminishing NO bioactivity, and disruption of proteins critical for excitation-contraction coupling (Wilson et al., 2002).

Our previous results are also supported by the results of the histology of the aorta, heart and kidney. The blood vessel showed intact layers across the groups. There was no derangement of cellular architecture in the heart and kidney. The organ weights presented no changes across the groups. Thus, treatment with GL preserved these major organs that regulate the cardiovascular system.

\section{CONCLUSION}

Our study suggests that $G$. latifolium leaves extract is cardioprotective. This is due to its ability to raise the serum concentrations of HDL-C and TAC, with a consequent decrease in the levels of LDL-c, TC, TG, TPP, and MDA. It also maintained the blood vessel integrity, cardiac muscles and renal structures, thus, resulting in the preservation of the cardiovascular system. This study therefore provides a basis for the use of this plant as an alternative in the prevention, management, or control of cardiovascular diseases.

\section{REFERENCES}

[1] Antai, A. B., Ofem, O. E., Ikpi, D. E., Ukafia, S., and Agiang, E. A.(2009). Phytochemistry and some haematological changes following oral administration of ethanolic root extract of Gongronemalatifolium in rats. Nigerian Journal of Physiological Sciences.24 (1):79-83.

[2] Atangwho, I. J., Ebong, P. E., Eyong, E. U., Williams, I. O., Eteng, M. U., and Egbung, G. E. (2009). Comparative chemical composition of leaves of some antidiabetic medicinal plants. African. Journal of Biotechnology. 8:4685-4689.

[3] Schneider, C., Rotscheidt, K., and Breitmaier, E. (1993). ZweineuePregnanesterglykosideausGongronemalatifoliu $m$ (Asclepiadaceae). J für Praktische Chemie/ChemikerZeitung. 335:532-536.

[4] Siedel, J., Hagele, E.O., Ziegenhorn, J., and Wahlefield, A.W. (1983). Reagent for the enzymatic determination of serum cholesterol with improved lipolytic efficiency, Clinical Chemistry. 20:1075.

[5] Eleyinmi, A. F. (2007). Chemical composition and antibacterial activity of Gongronema latifolium. Journal of Zhejiang University Science B. 8(5):352-358.

[6] Friedwald, W.T., Levy, R. I., Fredrickson, D.S. (1972). Estimation of the concentration of low-density lipoprotein cholesterol in the plasma, without the use of preparative ultracentrifuge. Clinical Chemistry.18:449502.

[7] Ohkawa, H., Ohishi, N. and Yagi, K. (1979). Assay for lipid peroxides in animal tissues by thiobarbituric acid reaction. Analytical Biochemistry. 95, 351-358.

[8] UnÜtzer, J., Klap, R., Sturm, R., Young, A., Marmon T., Shatkin, J. and Wells, K. (2000). Mental disorders and the use of alternative medicines: Results from a national survey. American Journal of Psychiatry. 157:1851-1857.

[9] Ugochukwu, N. H., and Cobourne, M. K. (2003). Modification of renal oxidative stress and lipid peroxidation in streptozotocin-induced diabetic rats treated with extracts from Gongronema latifolium leaves. Clinica Chimica Acta. 336(1-2):73-81.

[10] Ugochukwu, N. H., and Babady, N. E. (2002). Antioxidant effects of Gongronema latifolium in hepatocytes of rat models of non-insulin dependent diabetes mellitus. Fitoterapia 73(7-8):612-618.

[11] Owu, D. U., Nwokocha, C. R., Obembe, A. O., Essien, A. D., Ikpi, D. E.and Osim, E. E. (2012). Effect of Gongronema latifolium ethanol leaf extract on gastric acid secretion and cytoprotection in streptozotocin-induced diabetic rats. West Indian Medical Journal. 61(9): 853-860.

[12] Osuala, F. O., Anyadoh, S. O., and Nnoli, M. C. (2005). Antibacterial activities of two local medicinal plants, utazi (Gongronemalatifolium) and nchuanwu (Ocimium gratissimium). International Journal of Natural and Applied Sciences. 1: 36-39.

[13] Morebise, O., Fafunso, M. A., Makinde, J. M., Olajide, O. A.and Awe, E. O. (2002). Anti-inflammatory properties of the leaves of Gongronema latifolium. Phytotherapy Research. 16:75-77. 


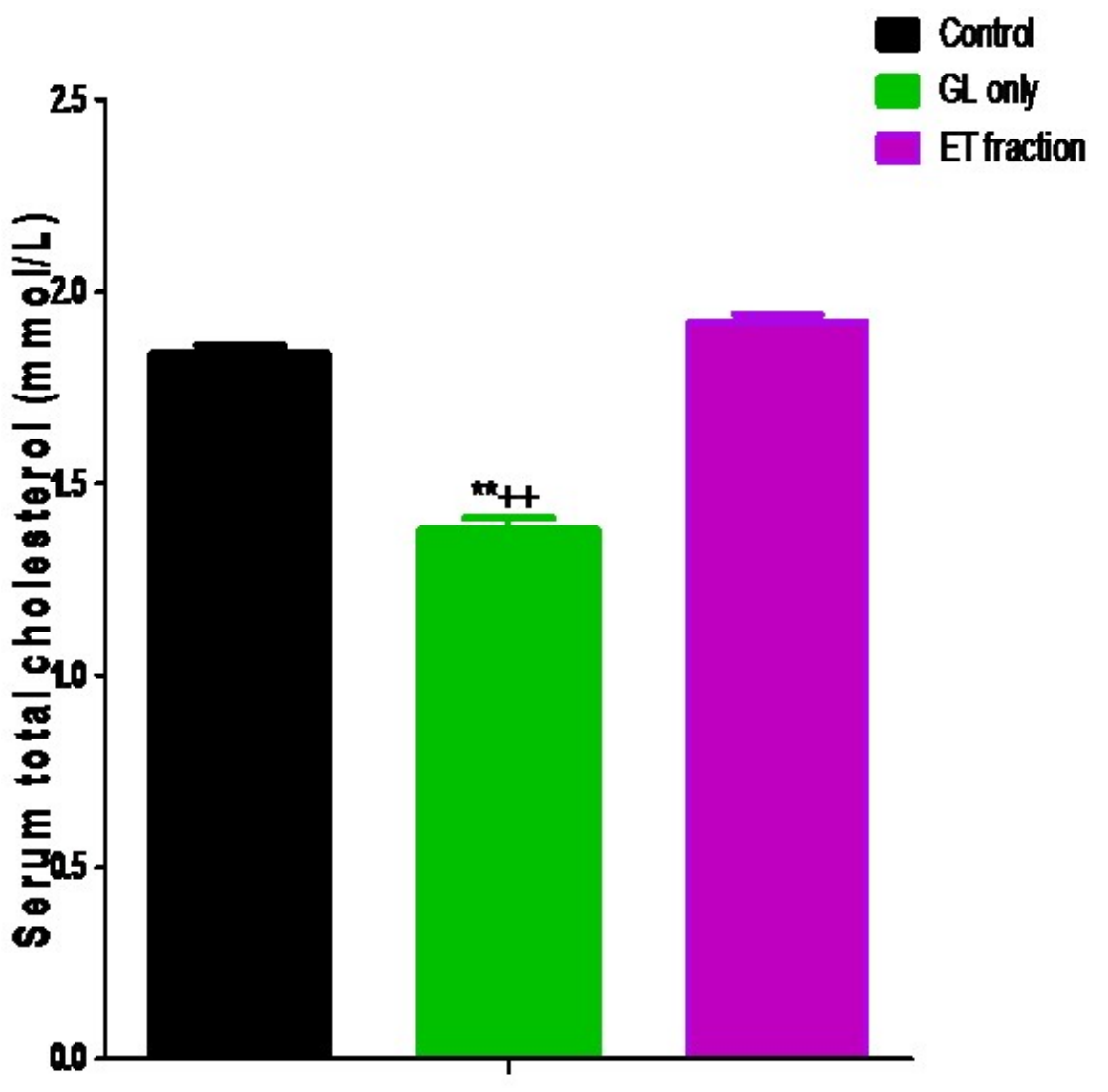

\section{Groups}

$* *=\mathrm{P}<0.01$ compared with control; $++=\mathrm{p}<0.01$ compared with ethyl acetate fraction, $\mathrm{n}=6$ Fig 1: Effect of ethanol extract and ethyl acetate fraction of $G L$ on serum total cholesterol

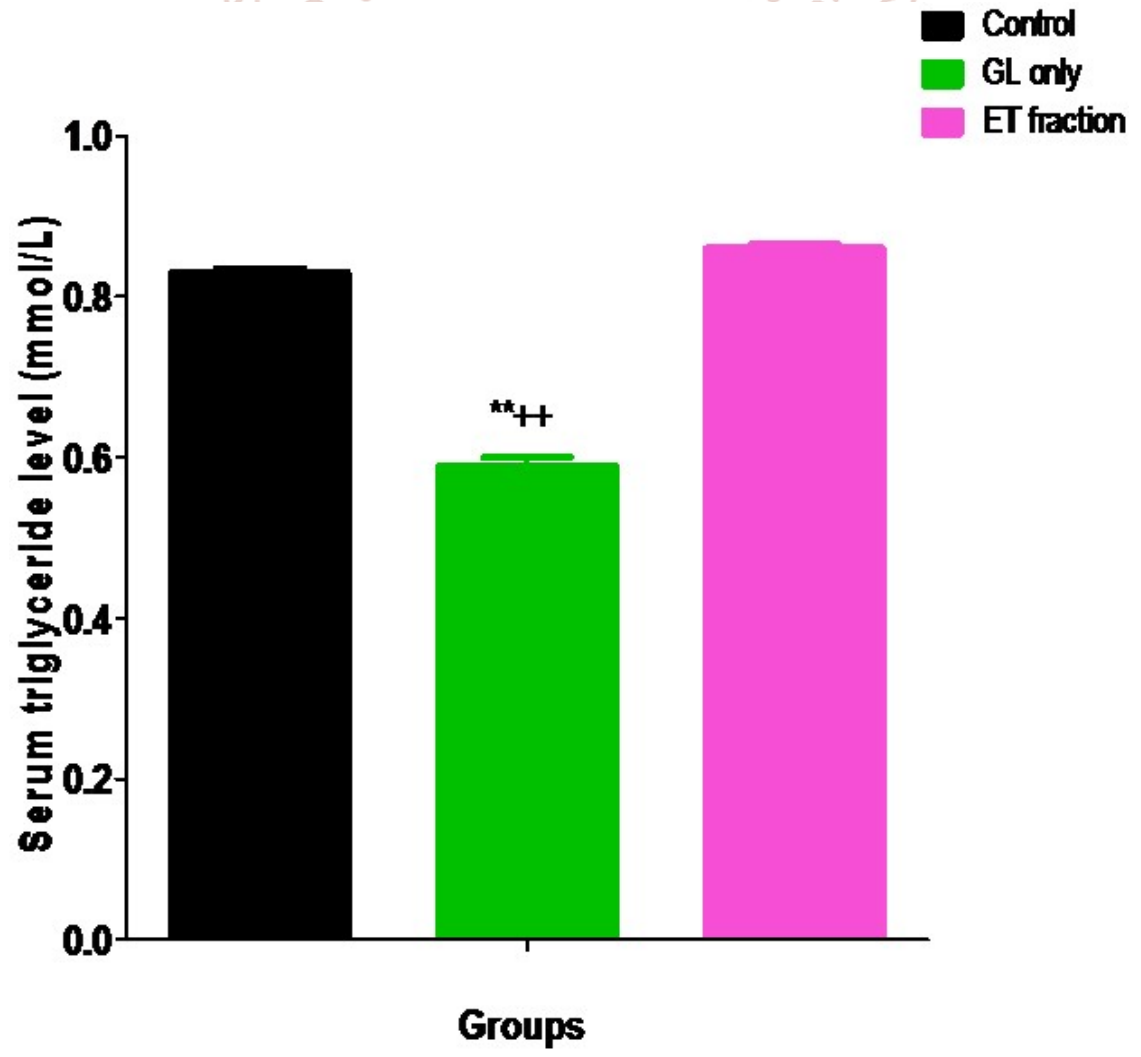

$* *=\mathrm{P}<0.01$ compared with control; $++=\mathrm{p}<0.01$ compared with ethyl acetate fraction, $\mathrm{n}=6$

Fig 2: Effect of ethanol extract and ethyl acetate fraction of $G L$ on serum triglyceride levels 


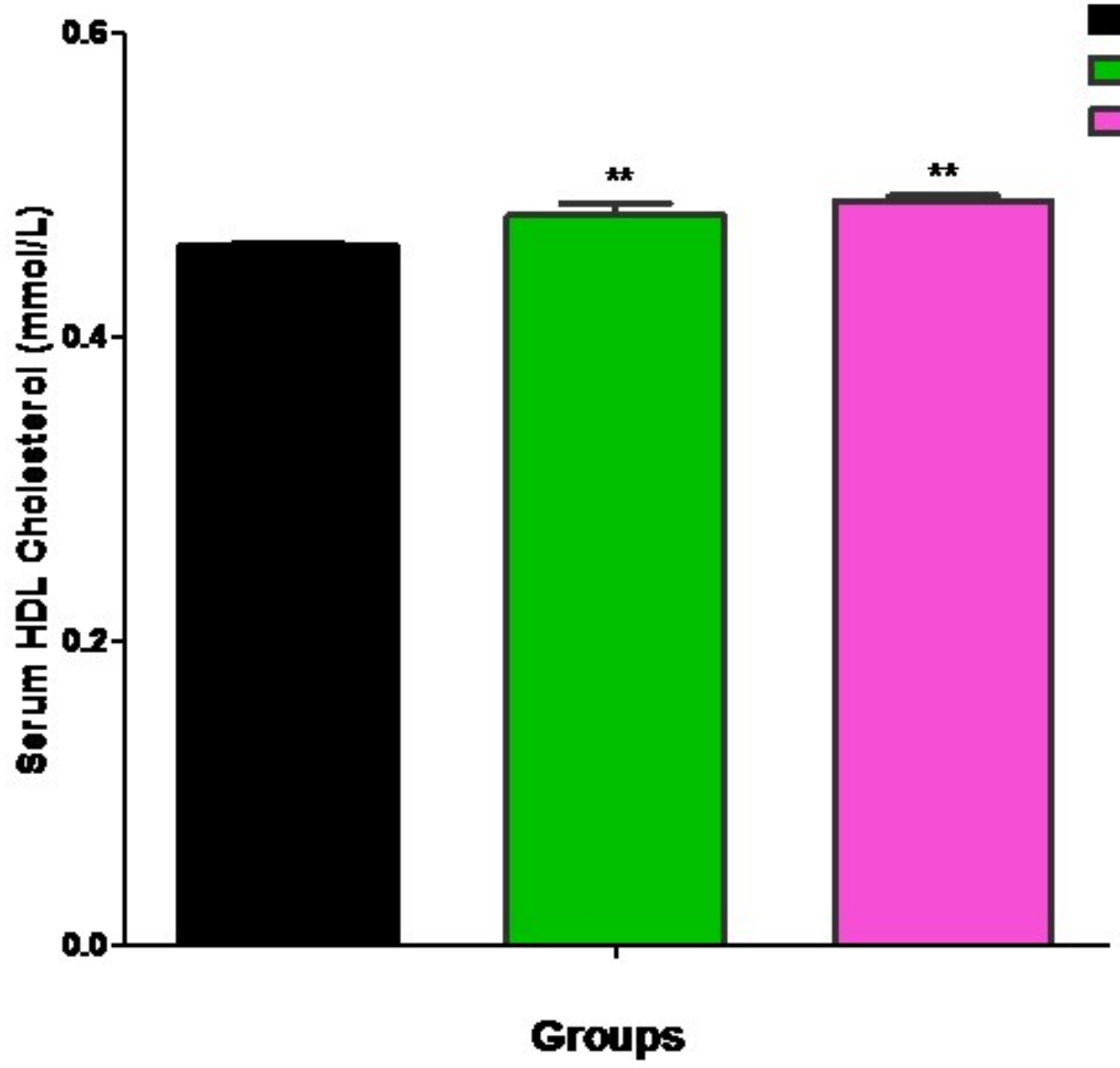

Control GL only ET fraction

$* *=\mathrm{P}<0.01$ compared with control, $\mathrm{n}=6$

Fig 3: Effect of ethanol extract and ethyl acetate fraction of GL on serum high density lipoprotein-cholesterol

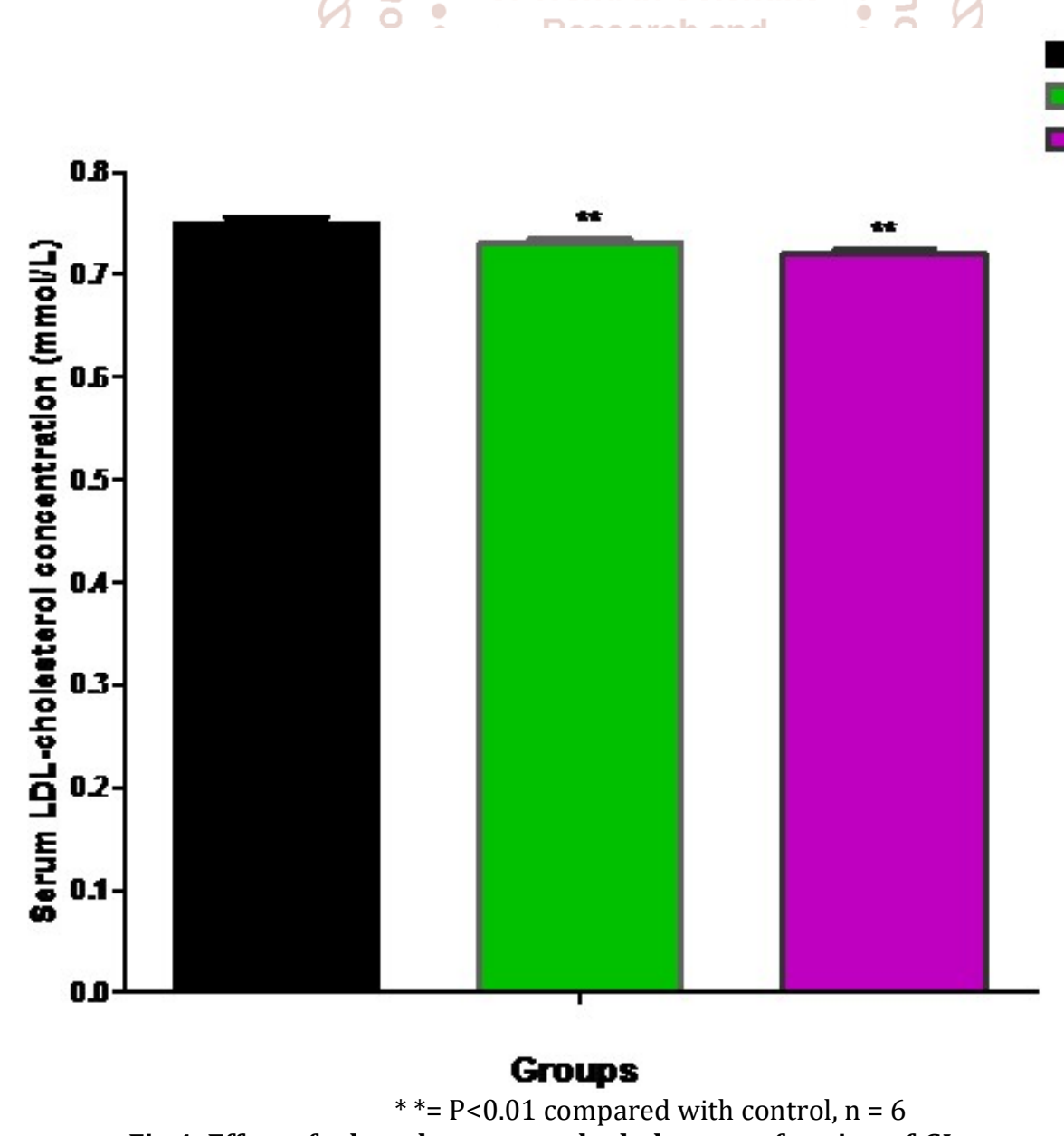

Fig 4: Effect of ethanol extract and ethyl acetate fraction of $G L$ on serum LDL-c 


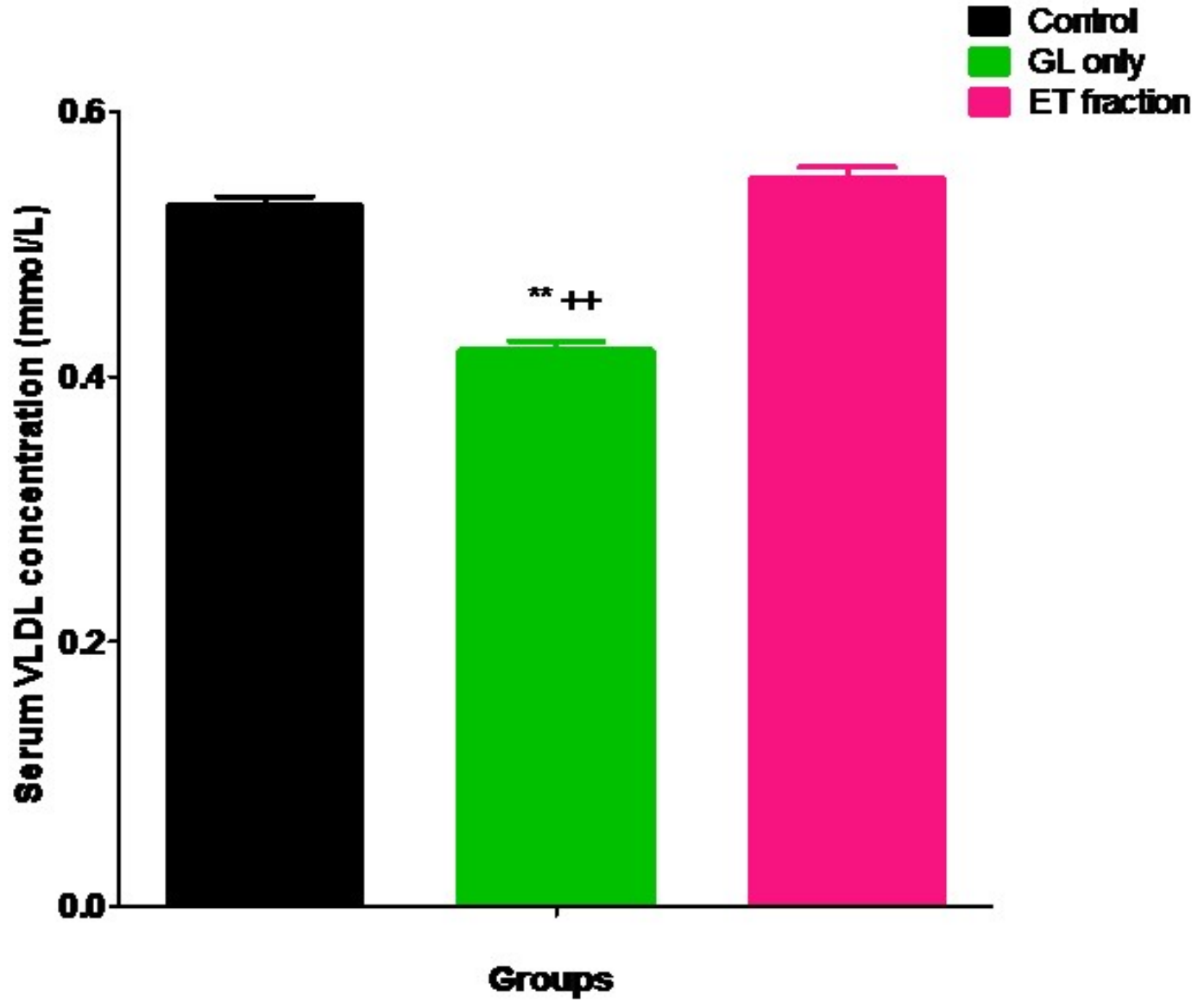

$* *=\mathrm{P}<0.01$ compared with control; $++=\mathrm{p}<0.01$ compared with ethyl acetate fraction, $\mathrm{n}=6$

Fig 5: Effect of ethanol extract and ethyl acetate fraction of $G L$ on serum VLDL-c

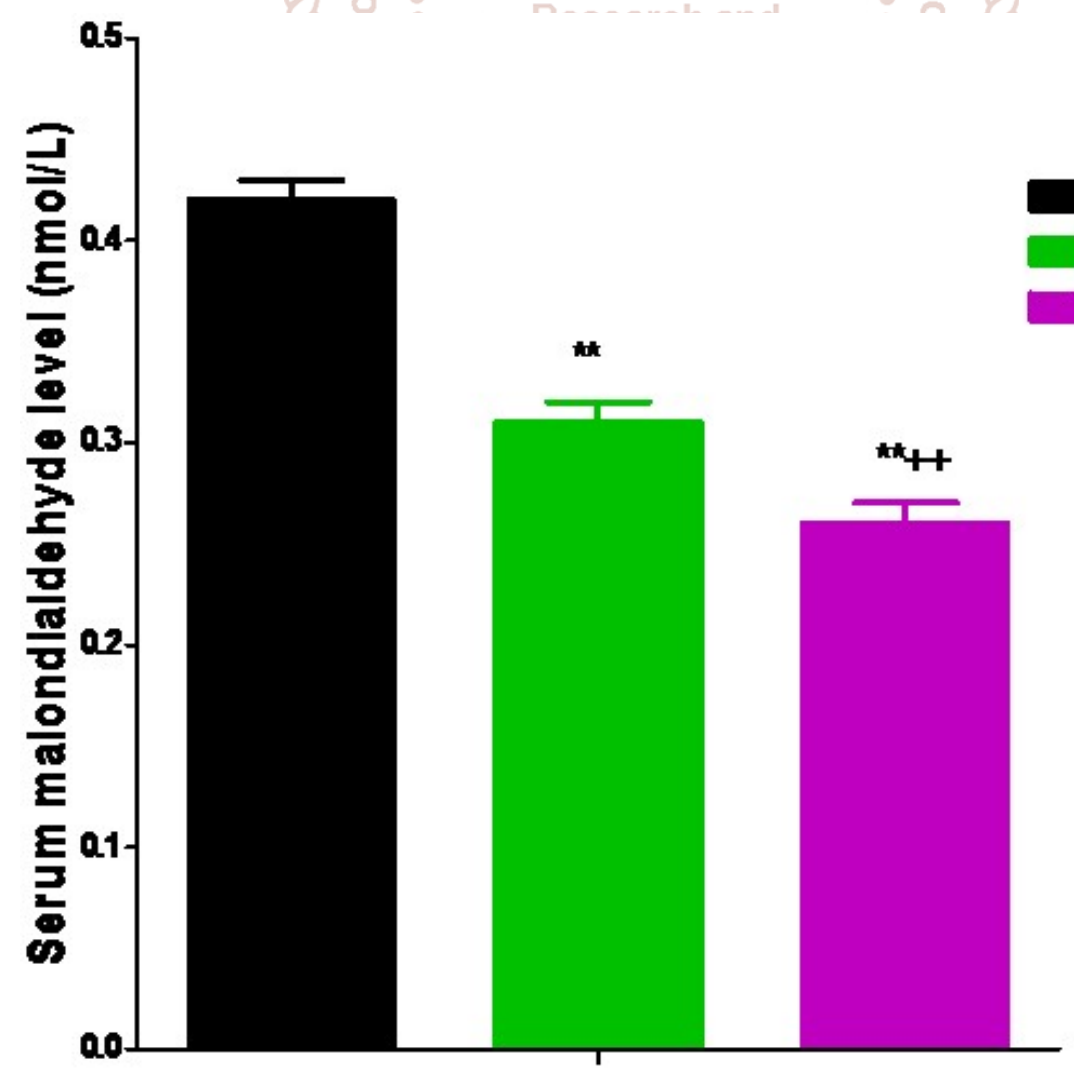

\section{Groups}

** $=\mathrm{P}<0.01$ compared with control; $++=\mathrm{p}<0.01$ compared with $G L, \mathrm{n}=6$

Fig 6: Effect of ethanol extract and ethyl acetate fraction of $G L$ on serum malondialdehyde 


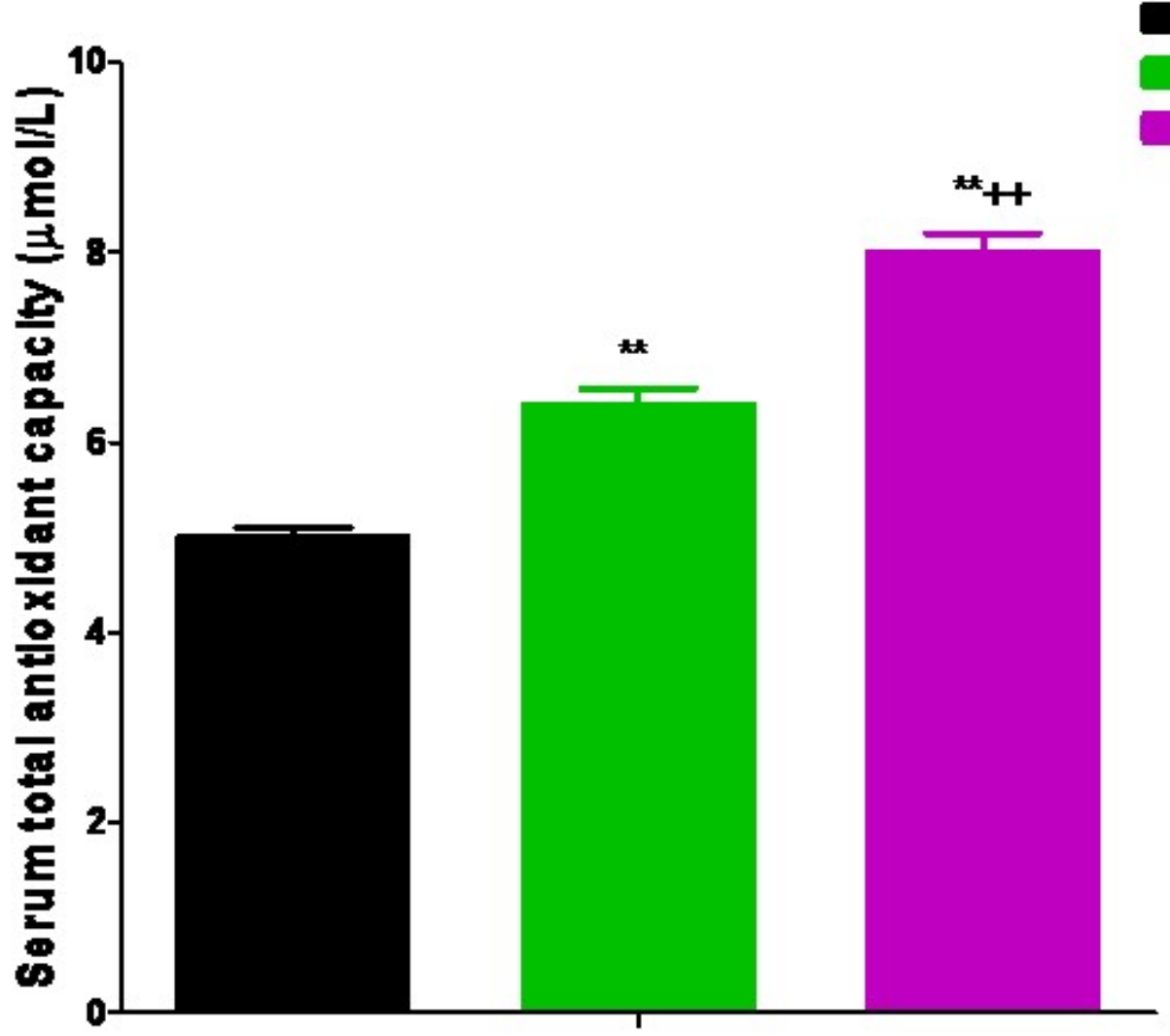

Control

GL onhy

ETfraction

\section{Groups}

$* *=\mathrm{P}<0.01$ compared with control; $++=\mathrm{p}<0.01$ compared with $G L, \mathrm{n}=6$

Fig 7: Effect of ethanol extract and ethyl acetate fraction of $G L$ on total antioxidant capacity

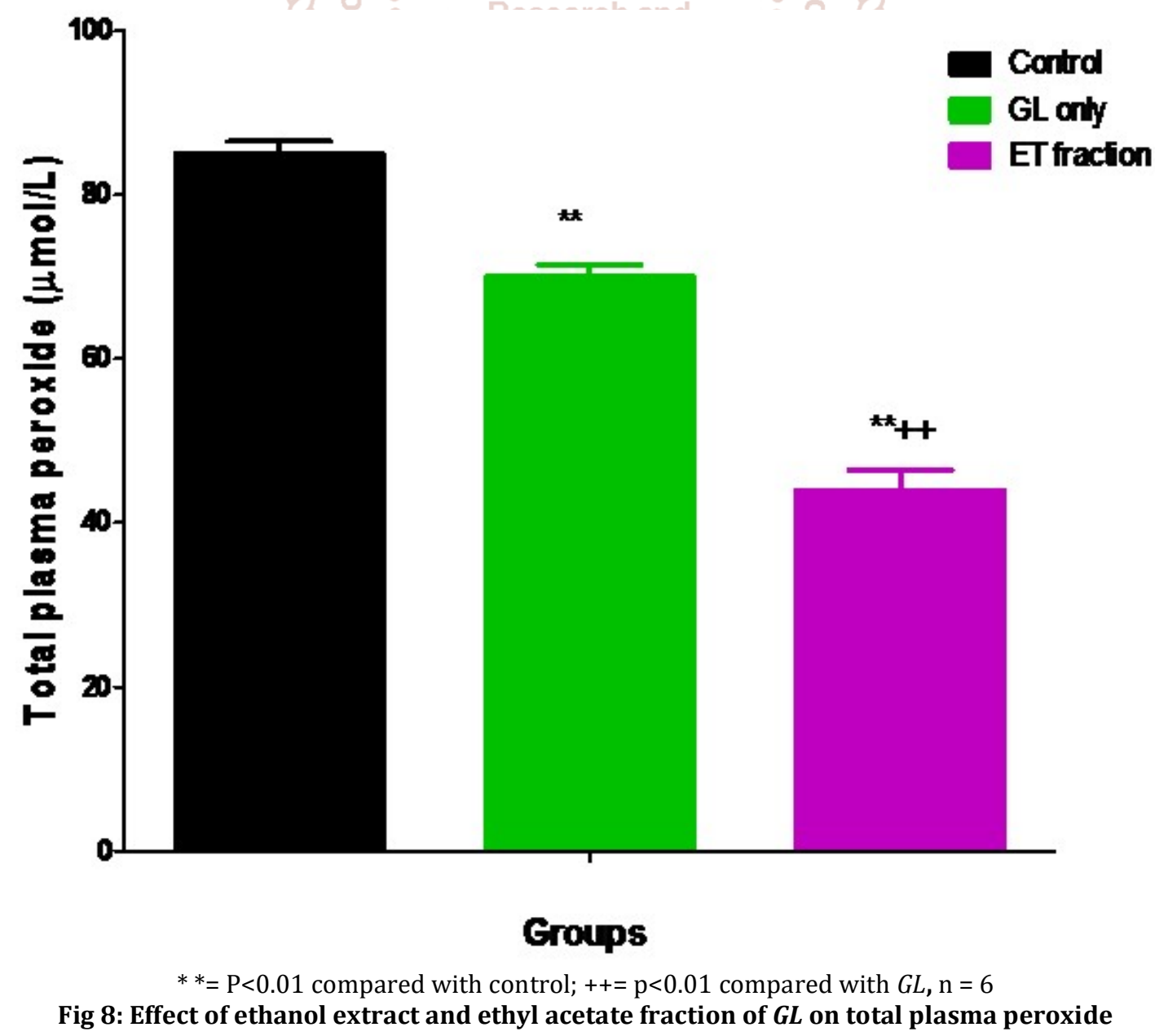




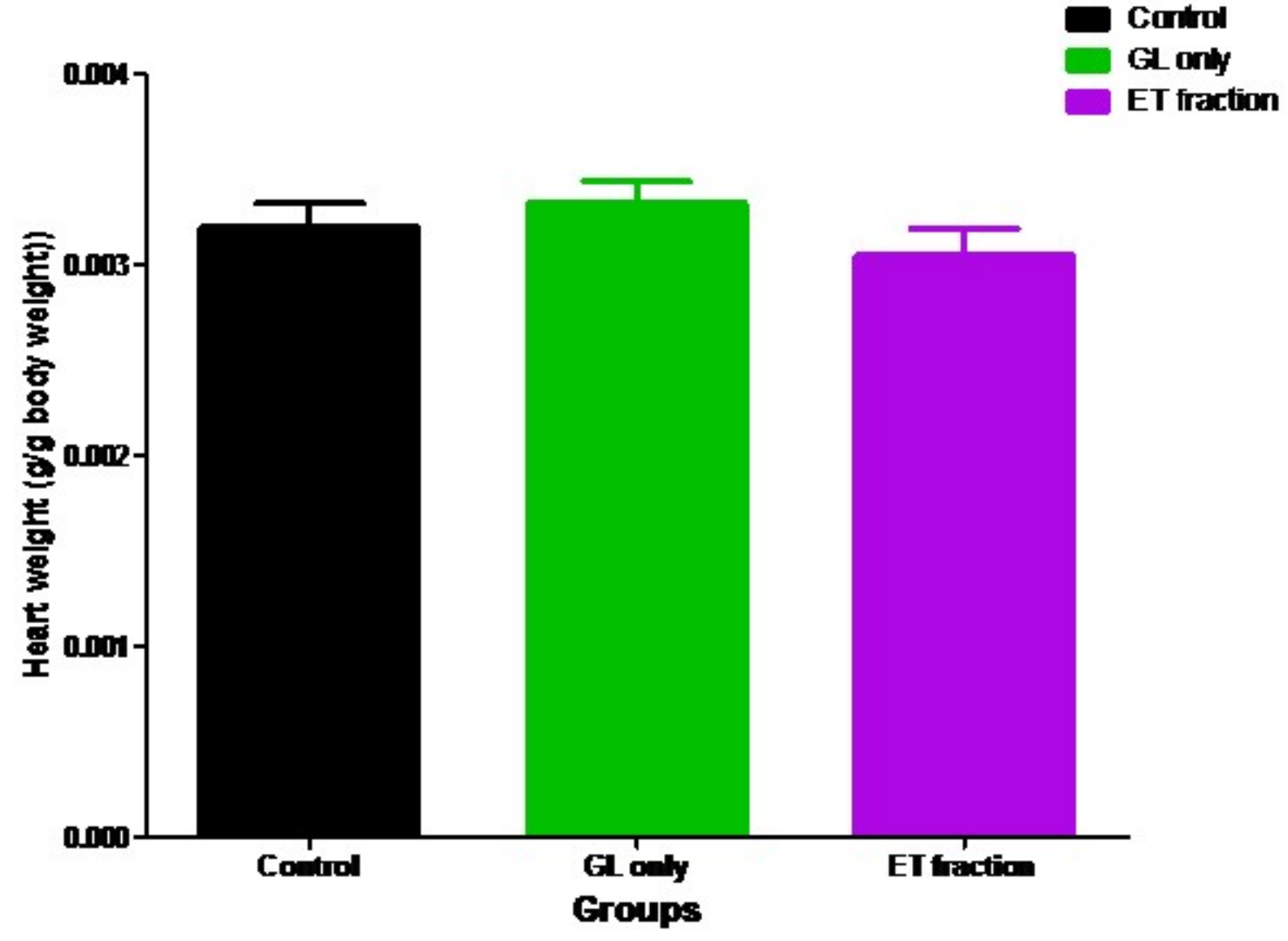

Fig 9: Effect of ethanol extract and ethyl acetate fraction of $G L$ on the weight of the heart

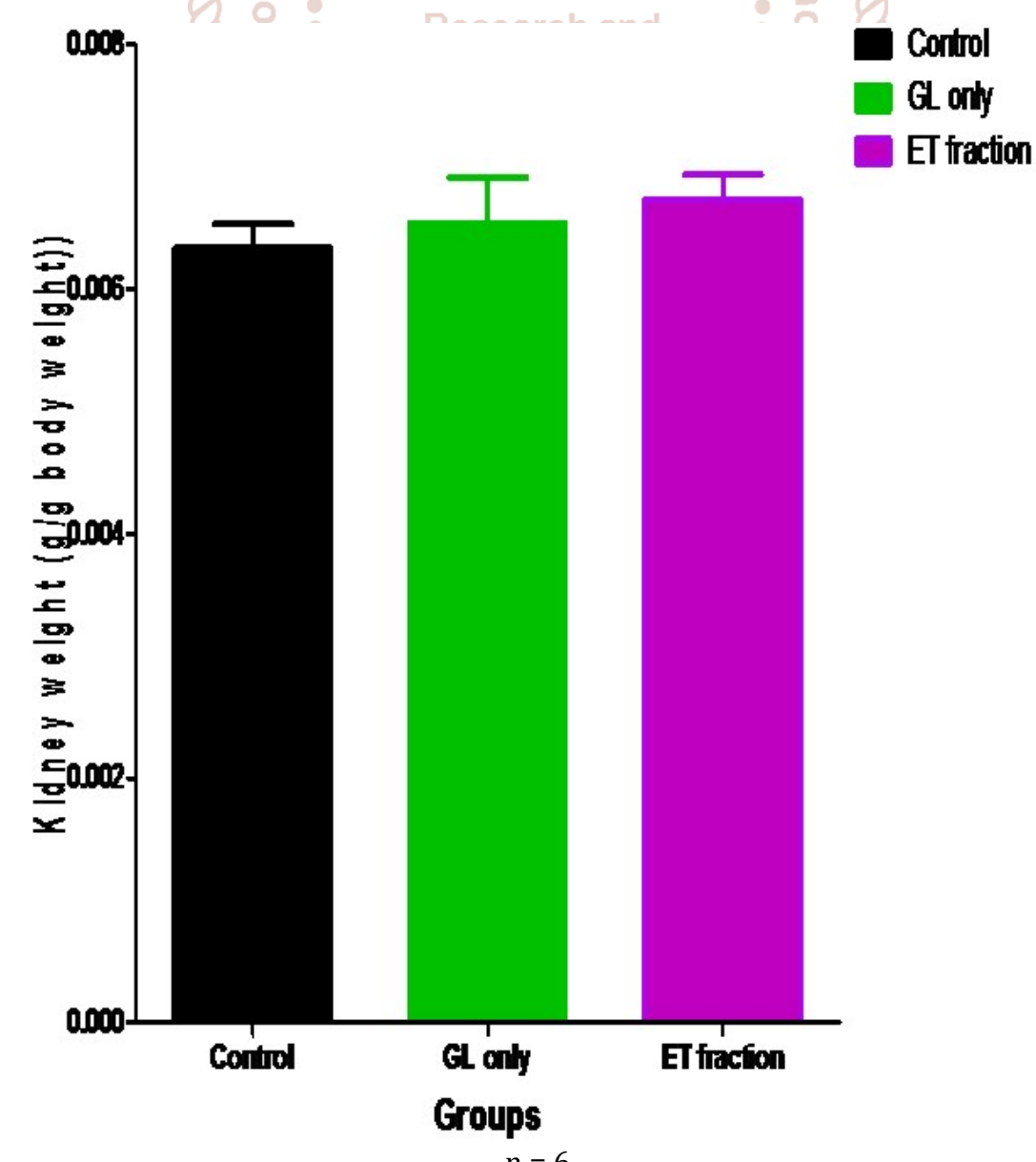

Fig 10: Effect of ethanol extract and ethyl acetate fraction of $G L$ on the weight of the kidney 

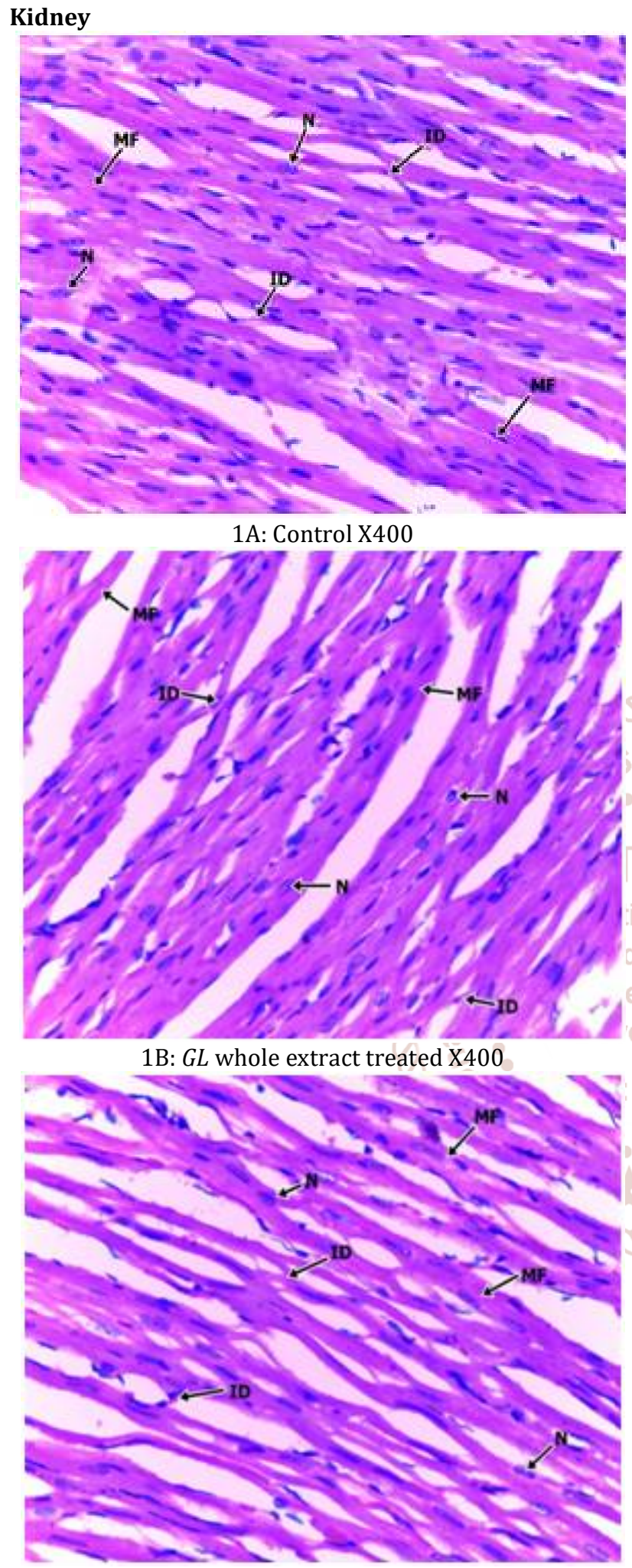

1C: Ethyl acetate fraction treated X400

Sections of cardiac muscles with intact cardiac myocytes separated by fibrous bands. The individual myocytes contain central ovoid nuclei with a clear zone at the poles. There are interdigitation of the muscle fibres and thin walled blood vessels.

$M F=M U S C L E$ FIBRES, N=NUCLEUS, ID=INTERCALATED DISC BV=BLOOD VESSEL

Plate 1: Photomicrographs of a cross section of the heart in the control, whole and ethyl acetate fraction of $G L$.

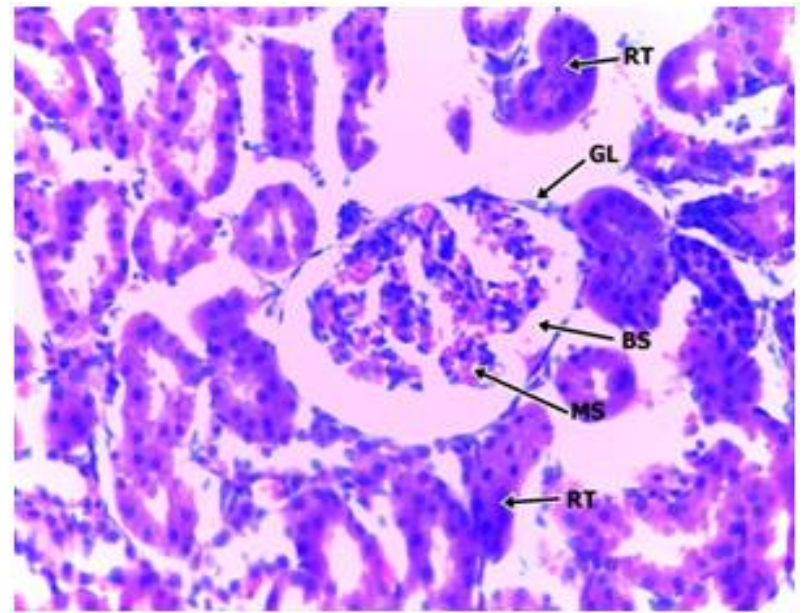

\section{A: Control X400}

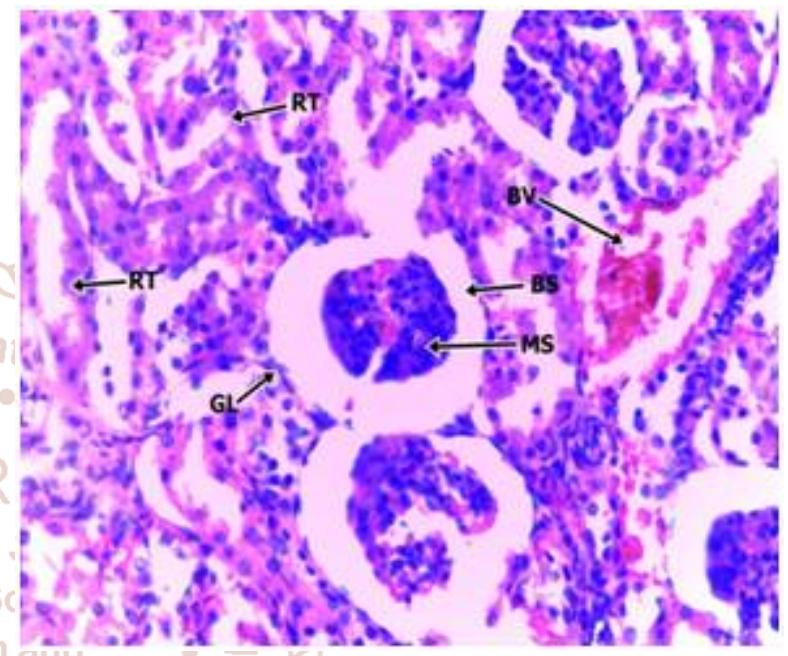

2B: Ethyl acetate fraction treated X400

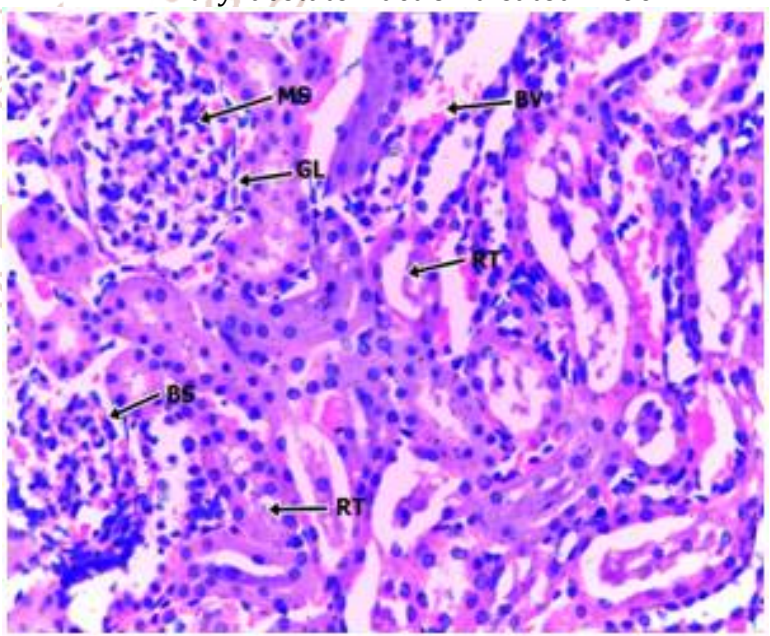

2C: GL whole extract treated X 400

Sections of the kidney show prominent glomeruli and renal tubules. The glomeruli have acellular mesangium composed of mesangial cells and arterioles with intact bowman spaces lined by flattened epithelial cells. The renal tubules are prominent with intact basement membrane and epithelium. They are lined by columnar to cuboidal epithelium with intact lumen. The intervening interstitium has congested blood vessels.

RT=Renal Tubules, MS=Mesangium, BS=Bowman Space, $\mathrm{GL}=$ Glomerulli, $\mathrm{BV}=$ Blood Vessel

Plate 2: Photomicrographs of a cross section of the kidney in the control, ethanol extract and ethyl acetate fraction of $G L$ 
International Journal of Trend in Scientific Research and Development (IJTSRD) @ www.ijtsrd.com eISSN: 2456-6470

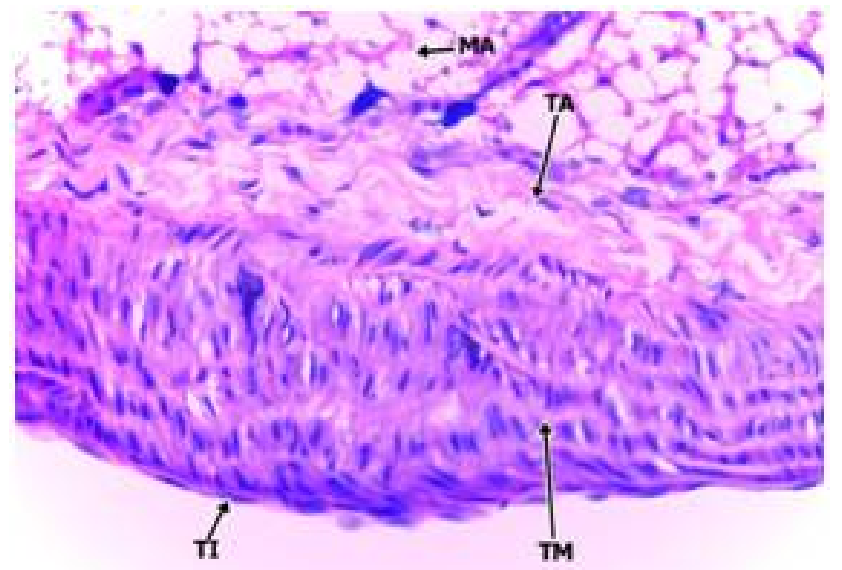

3A: Control X400

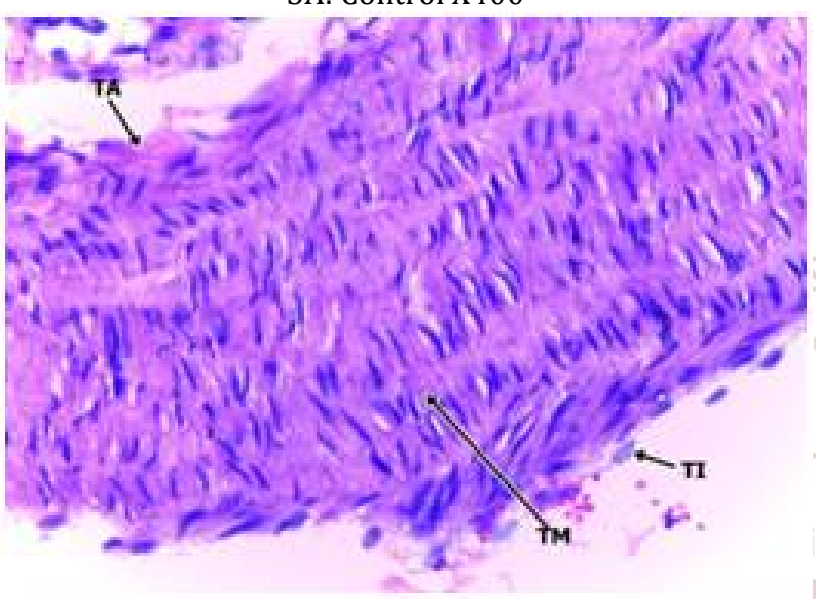

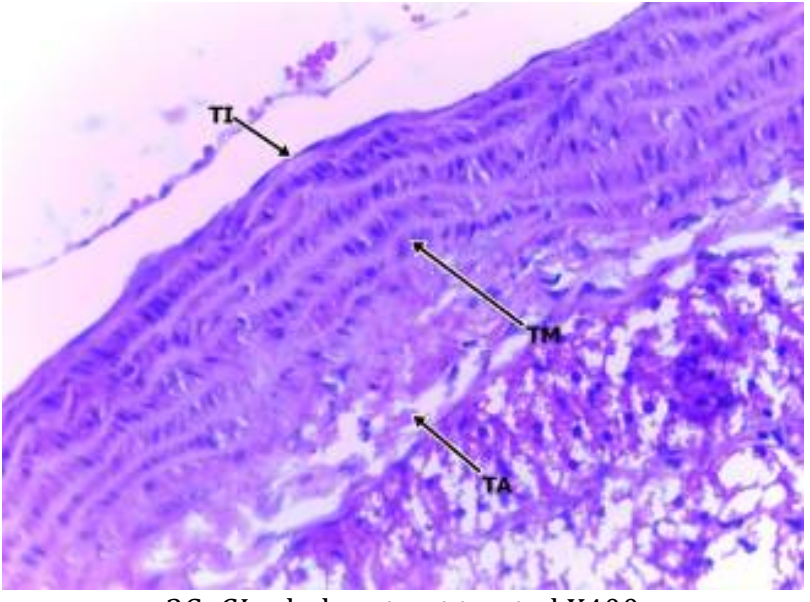

3C: GL whole extract treated X400

Section of the aorta shows intact layers comprising of outer tunica adventitia consisting of collagenous fibres, blood vessels and fibroblast. The intermediate tunica adventitia is thick and consists of regular arranged bundles of collagenous fibres with attached fibroblast. The tunica intima consists of intact simple endothelium overlying thin lamina propria.

TM=Tunica Media, TA=Tunica Adventitia, TI=Tunica Intima

Plate 3: Photomicrographs of a cross section of the aorta in the control, ethanol extract and ethyl acetate fraction of $G L$.

3B: Ethyl acetate fraction treated X400

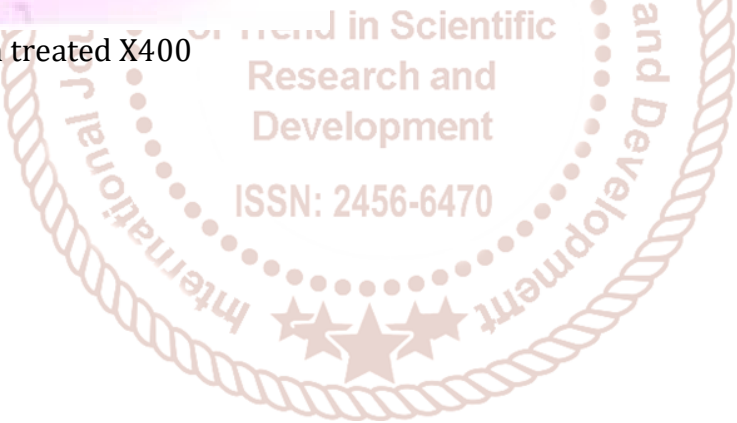

